\title{
Phosphate solubilizers enhance NPK fertilizer use efficiency in rice and legume cultivation
}

\author{
I. Duarah $\cdot$ M. Deka $\cdot$ N. Saikia $\cdot$ H. P. Deka Boruah
}

Received: 13 May 2011/Accepted: 28 September 2011/Published online: 21 October 2011

(C) The Author(s) 2011. This article is published with open access at Springerlink.com

\begin{abstract}
It has been reported that phosphate solubilizing bacteria (PSB) are the most promising bacteria among the plant growth promoting rhizobacteria (PGPR); which may be used as biofertilizers for plant growth and nutrient use efficiency. Moreover, these soil micro-organisms play a significant role in regulating the dynamics of organic matter decomposition and the availability of plant nutrients such as nitrogen $(\mathrm{N})$, phosphorus $(\mathrm{P})$, potassium $(\mathrm{K})$ and other nutrients. Through this study, the management of nutrient use efficiency by the application of PSB was targeted in order to make the applied nutrients more available to the plants in the rice (Oryza sativa) and yardlong bean (Vigna unguiculata) cultivation. Results have shown that the treatments with PSB alone or in the form of consortia of compatible strains with or without the external application of chemical NPK gave more germination index (G. I.) from 2.5 to 5 in rice and 2.7 to 4.8 in bean seeds. They also showed a higher growth in both shoot and root length and a higher biomass as compared to the control. This gives us an idea about the potentiality of these PSB strains and their application in rice and yardlong bean cultivation to get a better harvest index. Their use will also possibly reduce the nutrient runoff or leaching and increase in the use efficiency of the applied fertilizers. Thus, we can conclude that
\end{abstract}

I. Duarah $(\bowtie) \cdot$ N. Saikia · H. P. Deka Boruah Biotechnology Division, NEIST (CSIR),

Jorhat 785006, Assam, India

e-mail: ipduarah@gmail.com

M. Deka

Department of Biotechnology,

Guwahati University,

Gauhati, Assam, India the NPK uptake and management can be improved by the use of PSB in rice and yardlong bean cultivation, and their application may be much more beneficial in the agricultural field.

Keywords Fertilizer - Phosphate solubilizing bacteria . Oryza sativa - Vigna unguiculata - Germination index . Plant growth

\section{Introduction}

The application of mineral fertilizers is the most advantageous and the fastest way to increase crop yields. In the last few decades the rate of nitrogen $(\mathrm{N})$, phosphorous $(\mathrm{P})$ and potassium $(\mathrm{K})$ or NPK fertilizer application has tremendously increased in crop production (Adesmoye and Kloepper 2009). The excessive use of synthetic agrochemicals in crop production and in soil fertility management causes residue toxicity and environmental pollution (Tilman et al. 2002; Adesmoye and Kloepper 2009). This is due to low use efficiency of externally applied fertilizers by the plants, long-term application, leaching, and evaporation to atmosphere (Tilman 1998; Gyaneshwar et al. 2002; Kennedy et al. 2004). Therefore, the reduced use of synthetic agrochemicals in crop production and to maintain soil fertility by alternative means is the subject of investigation. The challenge is to continue sustainable agricultural crop production through minimization of harmful effect of fertilization.

Among the different alternatives, researchers hypothesized that plant growth promoting rhizobacteria (PGPR) could be a substitute to these (Kloepper and Schroth 1978; Glick 1995; Deka Boruah and Dileep Kumar 2002; Glick et al. 2007). Initially, though the application of PGPR was 
concentrated on biological control (Suslow 1982; Glick 1995), the use of PGPR is also being investigated for nutrient use efficiency in crop plants (Adesmoye and Kloepper 2009; Hariprasad and Niranjana 2009). They can be employed for efficient use of externally applied fertilizers (Vessey 2003; Adesmoye and Kloepper 2009). Among the different PGPR, phosphate solubilizing bacteria (PSB) on plant growth and development, their application in nutrient management and fertilizer use efficiency were earlier reported by several researchers (Rodriguez and Fraga 1999; Richardson 2001; Peix et al. 2001; Vessey 2003; Poonguzhali et al. 2007; Adesmoye and Kloepper 2009; Hariprasad and Niranjana 2009; Kim et al. 2009; Hong et al. 2010). The use of phosphate solubilizers in association with a host plant results in stimulation of growth of their host plants. Plant growth promotion may be achieved directly by the ability of the bacteria to fix nitrogen, sequester iron, facilitate phosphorus uptake, and produce phytohormones that triggers responses in a growing plant exerting multiple effects on plant growth and soil fertility improvement (Rodriguez and Fraga 1999; Peix et al. 2001; Glick et al. 2007; Hariprasad and Niranjana 2009; Kim et al. 2009). The PGPR are also reported to be involved in seed germination and somehow in the induction of $\alpha$-amylase, which helps to provide energy for the growth of roots and shoots (Beck and Ziegler 1989; Kaneko et al. 2002). The induction of $\alpha$-amylase also is a lead to the biosynthesis of phytohormones such as gibberellins that stimulates the plant growth (Fincher 1989; Kaneko et al. 2002).

Considering the authenticity of the aforesaid works, it can be put forward that if we introduce PSB in crop field with or without the application of chemical fertilizer, the doses of agrochemicals may be reduced as well as the crop productivity can be increased. Present investigation was carried out to study the assessment of the role of the PSB in NPK management and their effect in reduction of NPK use in the crop production as well as on germination and growth of Rice (Oryza sativa) and yardlong bean (Vigna unguiculata). Rice (Oryza sativa) is the most important grain with regards to human nutrition and caloric intake, providing more than one-fifth of the calories consumed worldwide by the human species (Paul et al. 2000). The yardlong bean (Vigna unguiculata), is a good source of protein, vitamin A, thiamin, riboflavin, iron, phosphorus, and potassium, and a very good source for vitamin $\mathrm{C}$, folate, magnesium, and manganese (National research council 2006). The production of these two crops needs external application of fertilizers. Considering the worldwide importance of these two crops, the application of phosphate solubilizers in rice and yardlong bean cultivation was considered to study the efficiency of PGPR in nutrient management. Though various factors determine the efficiency of PGPR in nutrient management, their application is increasing because of its ecofriendly and cost effective nature. In this study, the effort was given for the management of nutrient use efficiency through the application of PSB in order to make the applied nutrients more available to the plant.

\section{Materials and methods}

Strains

Seven numbers of PSB were taken for the experiment from the Biotechnology division, NEIST, Jorhat, which were selected on the basis of their higher phosphate solubilizing efficiency (more than 50\% p-solubilizing efficiency) on Pikovskaya medium (Pikovskaya 1948) and their positive response to the production of siderophore, plant growth regulators indole-acetic acid (IAA) and gibberellic acid (GA), etc. Details of the strains are given in Table 1.

\section{Experimental soil}

The soil used for the experiment was taken from the North East Institute of Science and Technology, Jorhat (NEIST) campus from a depth of $0-10 \mathrm{~cm}$ and laboratory analysis was done for physicochemical and biological characteristics. The soil $\mathrm{pH}$ was determined in 1:2.5 soil:water suspensions using an automatic glass electrode $\mathrm{pH}$ meter (Systronic model-361). The soil moisture content was determined after drying the soil samples at $105^{\circ} \mathrm{C}$ until a constant weight was obtained. The percentage of organic C was determined by Walkley and Black (1934) while phosphorus was evaluated by phosphomolybdic acid methods (Trivedy et al. 1998). Total nitrogen was estimated through Kjeldahl digestion.

Soil enzyme activity phosphatase was determined using the method described by Tabatabai and Bremner (1969). The optical density was recorded at $430 \mathrm{~nm}$ using an Analyticzena (Specord 210) spectrophotometer to determine how much $p$-nitrophenol was released and was quantified from standard curve of $p$-nirophenol. The 2,3,5-triphenyltetrazolium chloride (TTC) reduction technique (Casida 1964) was used to measure the soil dehydrogenase activity. The total dehydrogenase activity was calculated from standard curve of sodium hydrosulphide and total activity was expressed as mg INTF $\mathrm{g}^{-1}$ dry soil $\mathrm{h}^{-1}$. The urease activity was measured using the method described by $\mathrm{Mc}$ Garity and Myers (1967). The amount of $\mathrm{NH}_{4}-\mathrm{N}$ released by the urease enzyme was calculated using a referencecalibrated curve of $\mathrm{NH}_{4} \mathrm{OH}$ and expressed as $\mathrm{NH}_{4}-\mathrm{N}$ $\mathrm{mg} \mathrm{g}^{-1}$ of dry soil $\mathrm{h}^{-1}$. 
Table 1 Biochemical characters and the accession nos. of the strains under the study

\begin{tabular}{|c|c|c|c|c|c|}
\hline Strains & Name & Accession no. & Siderophore & IAA & GA \\
\hline ТP06 & Staphylococcus epidermidis & FJ887885 & + & + & + \\
\hline ТP08 & Erwinia tasmaniensis & FJ887889 & + & + & + \\
\hline TP13 & Pseudomonas aeruginosa & Not submitted & + & + & + \\
\hline TP14 & Pseudomonas aeruginosa & - & + & + & + \\
\hline TP16 & Pseudomonas aeruginosa & - & + & + & + \\
\hline TP27(7) & Bacillus subtilis & FJ887881 & + & + & + \\
\hline ТР373 & Pseudomonas aeruginosa & FJ887882 & + & + & + \\
\hline
\end{tabular}

\section{Experimental setup}

Plant growth promoting activity and NPK use efficiency of PSB on rice (Oryza sativa) and yardlong bean (Vigna unguiculata) was observed on filter paper in the laboratory condition and in earthen pots in the field by the methods of Deka Boruah and Dileep Kumar (2002). First, the earthen pots $(6 \mathrm{~cm} \times 12 \mathrm{~cm} \times 14 \mathrm{~cm})$ were filled with fertile soil with or without NPK (2:1:1) in 4 and $8 \mathrm{~g} \mathrm{pot}^{-1}$; i.e., 50 and $100 \%$ NPK of the recommended dose (the application dose for $100 \%$ and 50\% was 40:20:20 and 20:20:10 g NPK per $50 \mathrm{~kg}$ of soil). The sources for NPK were urea, superphosphate and murate of potash, respectively. For the study on filter paper solutions of NPK were made at 50 and $100 \%$ concentrations and applied on filter paper. The treatments made for the entire period of investigation for both the plants were-treatment 1 (T1): garden soil; treatment 2 (T2): garden soil + NPK (100\%); treatment 3 (T3): garden soil + NPK (50\%), treatment 4 (T4): garden soil + TP08; treatment 5 (T5): garden soil + TP16; treatment 6 (T6): garden soil $+\mathrm{TP} 373$; treatment 7 (T7): garden soil + consortia (TP06 + TP13 + TP14 + TP 27(7)); treatment 8 (T8): garden soil + TP08 $+50 \%$ NPK; treatment 9 (T9): garden soil + TP16 + 50\% NPK; treatment 10 (T10): garden soil $+\mathrm{TP} 373+50 \%$ NPK; treatment 11 (T11): garden soil + consortia $[\mathrm{TP} 06+\mathrm{TP} 13+\mathrm{TP} 14+$ TP 27(7)] + 50\% NPK.

Surface sterilization and seed bacterization of both rice and yardlong bean seeds was done according to the method of Deka Boruah and Dileep Kumar (2002). For the rice seeds, according to Colmer (2003); the flask containing the seeds was covered with carbon paper in order to provide a dark condition for the emergence of coleoptiles (S1 stage) and then surface sterilized. For seed bacterization, surface sterilized seeds were then imbibed in a bacterial cell suspension having the colony forming unit (cfu) $1.2 \times 10^{7}$ for $4 \mathrm{~h}$ in a reciprocal shaker adjusted to $60 \mathrm{rpm}$. After $4 \mathrm{~h}$ of imbibing, the seeds were removed and dried under laminar air flow. The seeds were then transferred to a filter paper and earthen pots; allowed to grow for 15 days. Seeds (without seed bacterization) treated with PNS (Plant nutrient solution) alone was considered as control. The seeds on filter papers were then allowed to germinate under controlled condition at $25{ }^{\circ} \mathrm{C}$ in plant growth chamber with $10 \mathrm{~h}$ photoperiod, while the earthen pots were transferred to the greenhouse. The effect of PSB on root length, shoot lengths, total root and shoot biomass was recorded after 15th day. All the treatments were repeated at least twice with six replications each.

Availability and uptake of NPK

Availability of NPK was analyzed in the soil of each treatment at initial stage and after 30 days of treatment. Effect of PSB on nutrient uptake of rice and yardlong bean was analyzed in the leaves of 30 days old seedlings. Total $\mathrm{N}$ was analyzed by Kjeldahl digestion methods, total $\mathrm{P}$ in plant samples was estimated by ammonium-molebdate method in acid digestion methods; whereas $\mathrm{K}$ was analyzed by flame photometrically.

Speed of germination (G. I. index)

Number of seedlings emerging daily were counted from the day of planting the seeds in the medium till the time germination (up to 5th day) is complete. Thereafter, a germination index (G. I.) is computed by using the following formula (Elliott 2001):

G. I. index $=n / d$,

where, $n=$ number of seedlings emerging on day ' $\mathrm{d}$ '; $d=$ day after planting.

Shoot length, root length and biomass

The root length, shoot lengths, total root and shoot biomass of both the yardlong bean and rice seedlings were recorded after 15th day of treatment; till the V3 stage (collar formation of leaf 3 on main stem) in case of rice. All the treatments were repeated at least five times with five replications each. 
Amylase activity

The amylase activity in seeds at the post-germination stage and on the leaves of seedlings (5th day of germination) was assayed by the method of Thiammaiah (2004). Extraction of $\alpha$-amylase was done in $10 \mathrm{mM}$ ice cold $\mathrm{CaCl}_{2}$ solution for $3 \mathrm{~h}$ at room temperature. For free $\beta$-amylase, $1 \mathrm{gm}$ acetone defatted material was crushed with $66 \mathrm{mM}$ phosphate buffer ( $\mathrm{pH} 7.0$ ) buffer at $4{ }^{\circ} \mathrm{C}$ and supernatant was taken for $\beta$-amylase assay. For the enzyme assay, $1.0 \mathrm{~mL}$ properly diluted enzyme was mixed with $1 \%$ starch solution and then incubated for $15 \mathrm{~min}$ at $27^{\circ} \mathrm{C}$. Then the reaction was stopped by adding di-nitro salicylic acid solution and incubated in a boiling water bath for $5 \mathrm{~min}$ and $1.0 \mathrm{~mL}$ of sodium potassium tartarate was added, the absorbance was recorded under $560 \mathrm{~nm}$ against the blank. The amylase activity was calculated by using a standard curve of maltose and expressed as $\mu \mathrm{g}$ of maltose released per gm of fresh weight of the material in $1 \mathrm{~h}$.

\section{Statistical analysis}

Statistical analysis were carried out through one-way analysis of variance (ANOVA) to see the significance difference and the mean of treatments were compared according to Tukey's test at $p \leq 0.001, p \leq 0.01$ and $p \leq 0.05$. All the analysis was done in Graph pad Prism5 programme.

\section{Results and discussions}

The experimental soil

The $\mathrm{pH}$ of the experimental soil was moderately acidic (5.2-5.9) in all the soil samples before and after treatments. However, a decrease in $\mathrm{pH}$ from 5.9 to 5.6 was found in $100 \%$ NPK treated soil for rice and 5.9 in yard long bean. The moisture content and the carbon content of the soil were estimated at 25.9 and $0.3-1.2 \%$, respectively. The respective experimental soil $\mathrm{pH}$ is suitable for growing both yardlong bean and rice. This is supported by the earlier studies as yardlong bean prefer a light, well-drained soil with a $\mathrm{pH}$ of 5.5-6.8; while the rice cultivation needs $\mathrm{pH}$ of 5.0-6.0 (National research council 2006; Paul et al. 2000).

The dehydrogenase activity of soil in case of both rice and bean cultivation was found to be decreased with the amendment of NPK fertilizer, which is evident in $100 \%$ NPK (1.51-0.77 $\left.\mathrm{mg} \mathrm{g}^{-1} \mathrm{~h}^{-1}\right)$ and 50\% NPK (2.10-0.83 $\mathrm{mg} \mathrm{g}^{-1} \mathrm{~h}^{-1}$ ) after the 30th day of the experiment (Table 2). In contrast to this, a significant increase of dehydrogenase activity $(p \leq 0.05)$ was found in PSB treated (without NPK treatment) soil over the control. Whereas no such increase was found in case of soil treated with both NPK and PSB. Dehydrogenase activity is commonly used as an indicator for biological activity, i.e., it can be used to indicate the total microbial population. The decrease in dehydrogenase activity in NPK amended soil is contributed by its toxic effect on total soil microbes. This explanation can also be co-related with the work of Tilak et al. (2005), as he noted that the intensive use of chemical fertilizer results in increased soil salinity, which leads to deterioration of soil health. Dehydrogenase enzyme exhibits lower activity at higher doses of pesticides, which was reported by Baruah and Mishra (1986). However, the decrease in dehydrogenase activity may also be contributed by the fact that indicator TTC (triphenyltetrazolium chloride) yield less formazan for the interference by the NPK with the electron donors (Casida 1977).

On the other hand, the phosphatase and urease activity for both rice and yardlong bean cultivated soil was being increased in all the treatments as compared to control plant. The increment of phosphatase activity was $0.92-1.35$ to $2.09-2.40 \mathrm{mg} \mathrm{g}^{-1} \mathrm{~h}^{-1}$ and the urease activity was found to be increased from $0.32-0.49$ to $1.0-3.4 \mathrm{mg} \mathrm{g}^{-1} \mathrm{~h}^{-1}$. In case of the treatments only with NPK fertilizer (50 or $100 \%$ dose), only a slight increment was seen for both the phosphatase and urease activity. However, the increment was significantly higher ( $p \leq 0.05$ ) when treated with PSB alone. The lower enzyme activity in the NPK-treated soil may be contributed by the low population of phosphate solubilizers and nitrogen fixers. Results indicated that the application of agrochemicals significantly inhibits the population of phosphate solubilizers and nitrogen fixers, which was reported earlier by Balamurugan et al. (2010). It may be stated that the increase in phosphatase activity in PSB-treated soil is an indication of the increased soil fertility and improvement in the phosphate solubilization. Similarly, increase in urease activity in PSB-treated soil may be defined as the infrequent participation of PSBs in the nitrogen fixation. The efficiency of Phosphorus biofertilizers in biological nitrogen fixation was also reported by Kucey et al. (1989) and Gyaneshwar et al. (2002).

\section{Effect on NPK use efficiency}

The NPK concentration, i.e., the availability was estimated in the soil of both rice and longyard bean at the first day and after 30th day of the treatments. Data presented in the Tables 3 and 4 showed that the NPK concentration in soil at the first day was $0.10 \pm 0.001,0.002 \pm 0.0006$ and $0.08 \pm 0.002 \%$, respectively, which was found to decreased up to $0.09 \pm 0.002,0.001 \pm 0.0001$ and $0.07 \pm 0.002 \%$ due to uptake by the plants after 30 days. This higher increment over the control is due to the uptake 


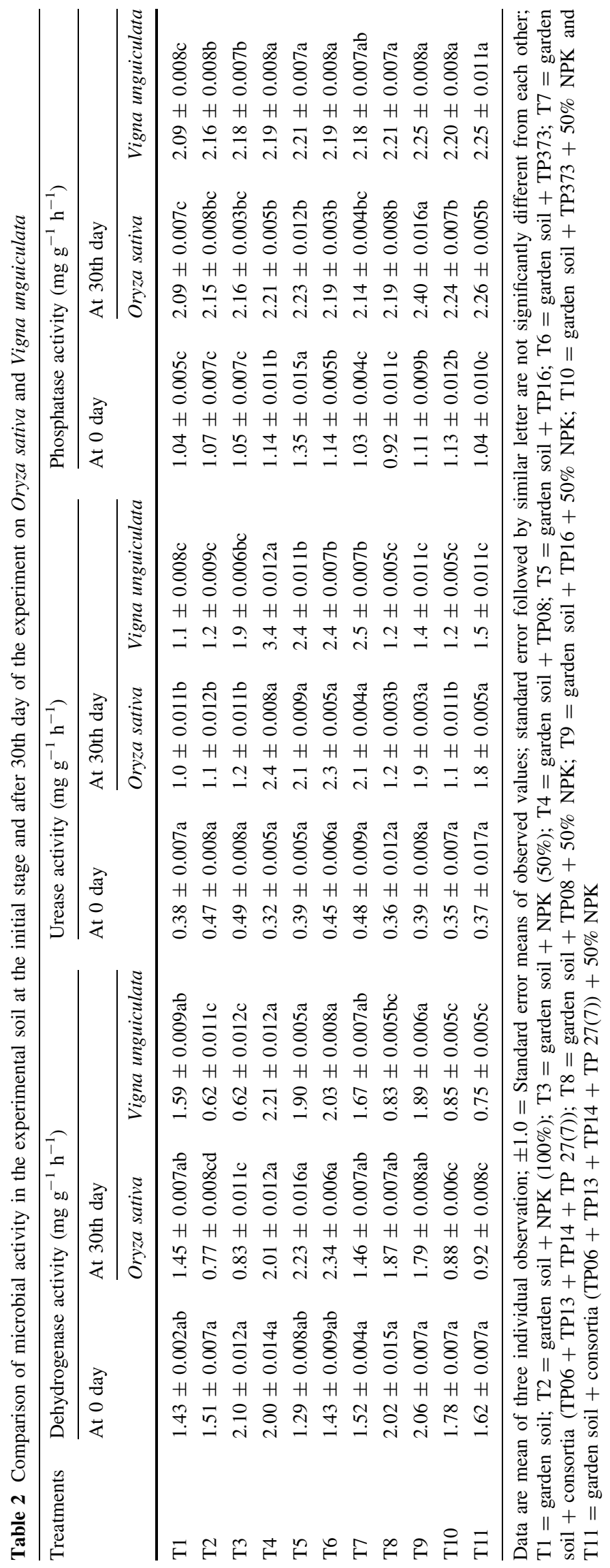




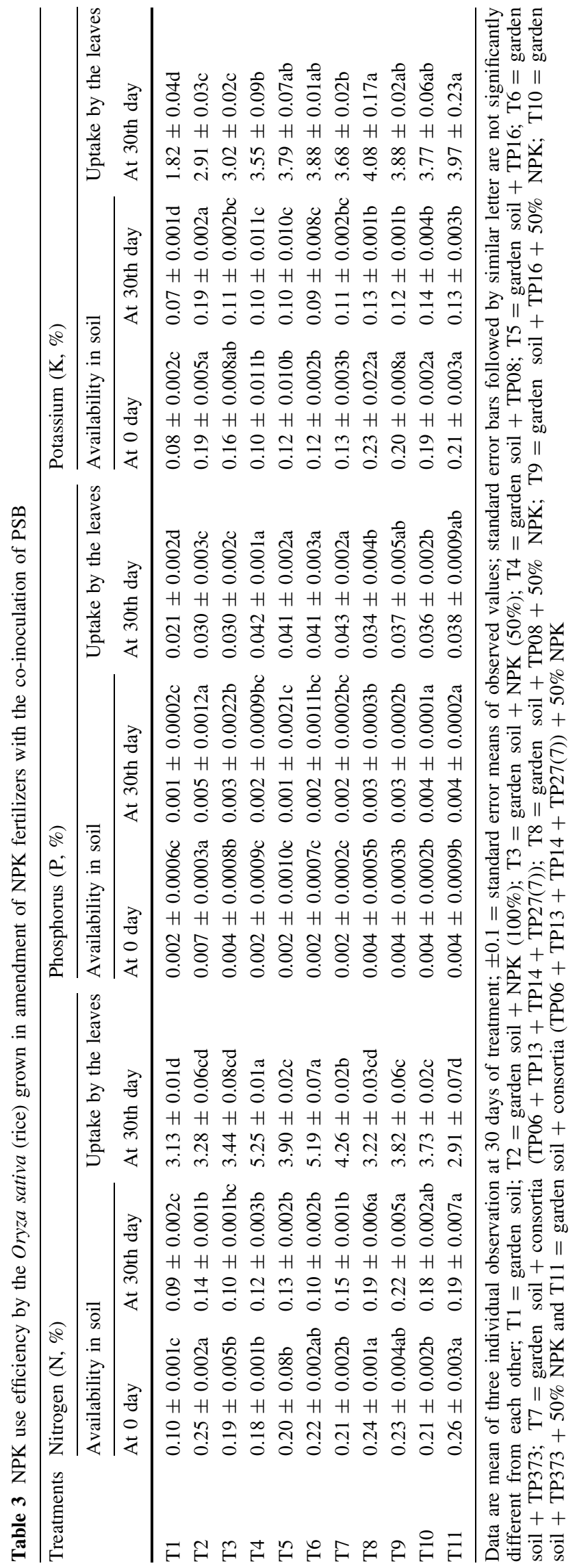

by the plants in other treatments with PSB and NPK fertilizer as it was decreased up to a significantly $(p \leq 0.05)$ higher quantity.

Again the uptake of NPK was analyzed by estimating their concentration in the leaves. In the case of the treatments with PSB alone or in consortia of compatible strains viz., TP06, TP13, TP14 and TP 27(7); and with or without the amendment of NPK fertilizer, the higher concentration of NPK was recorded in the leaves of both rice and longyard bean. The NPK concentration in leaves of rice was recorded at $3.22-5.25,0.036-0.043$ and $0.10-0.23 \%$ respectively, which is significantly higher $(p \leq 0.05$ to $0.01)$ over the control plant $(3.13-3.22,0.021-0.023 \%$ and $1.82-2.28 \%$, respectively). The same increment was also recorded in the case of longyard bean also. After the application of biofertilizers (PSB) and chemical fertilizers (urea, murate of potash and superphosphate); the NPK concentrations of both leaves and the soil are recorded at an inclined amount. A relatively higher uptake of NPK can be predicted in the treatment of externally applied NPK with the co-inoculation of PSB. This may be due to the presence of PSB which helps in the solubilization and thereby the uptake of NPK with or without NPK amendment by the plants. Increasing the availability of nutrients for the plants uptake with the application of biofertilizer was also reported earlier by several workers (Glick 1995; Rodriguez and Fraga 1999; Vessey 2003).

It was also seen that there was little difference in the level of NPK uptake by the plants with the treatments containing NPK in 50 and $100 \%$ dose. Thus, it is seen that a reduced application of NPK with the application of PSB can give a better result in NPK use efficiency. This is because of the low uptake of the externally applied NPK fertilizers by the crop plants which was also reported by the researchers Tilman (1998), Gyaneshwar et al. (2002) and Kennedy et al. (2004). It was also reported that the excessive application of NPK or in their higher dose, salt toxicity may be occurred, which may be accounted for the low nutrient uptake and reduced growth (Tilak et al. 2005; Nahed and Aziz 2007).

Effect on seed emergence

Seed vigor is an important quality parameter to study the effect of PGPR in its germination. The effect of PSB on germination index is described in the Table 5 and Fig. 1. The seed having higher germination index (G. I.) is seen to be more vigorous than the others. A significantly higher G. I. $(p \leq 0.01)$ is obtained with the application of PSB alone or in the form of consortia of compatible strains, with or without external application of chemical NPK as compared to the control. Results have shown that the G. I., both in the case of rice and yardlong bean seed lot is increased; in rice 


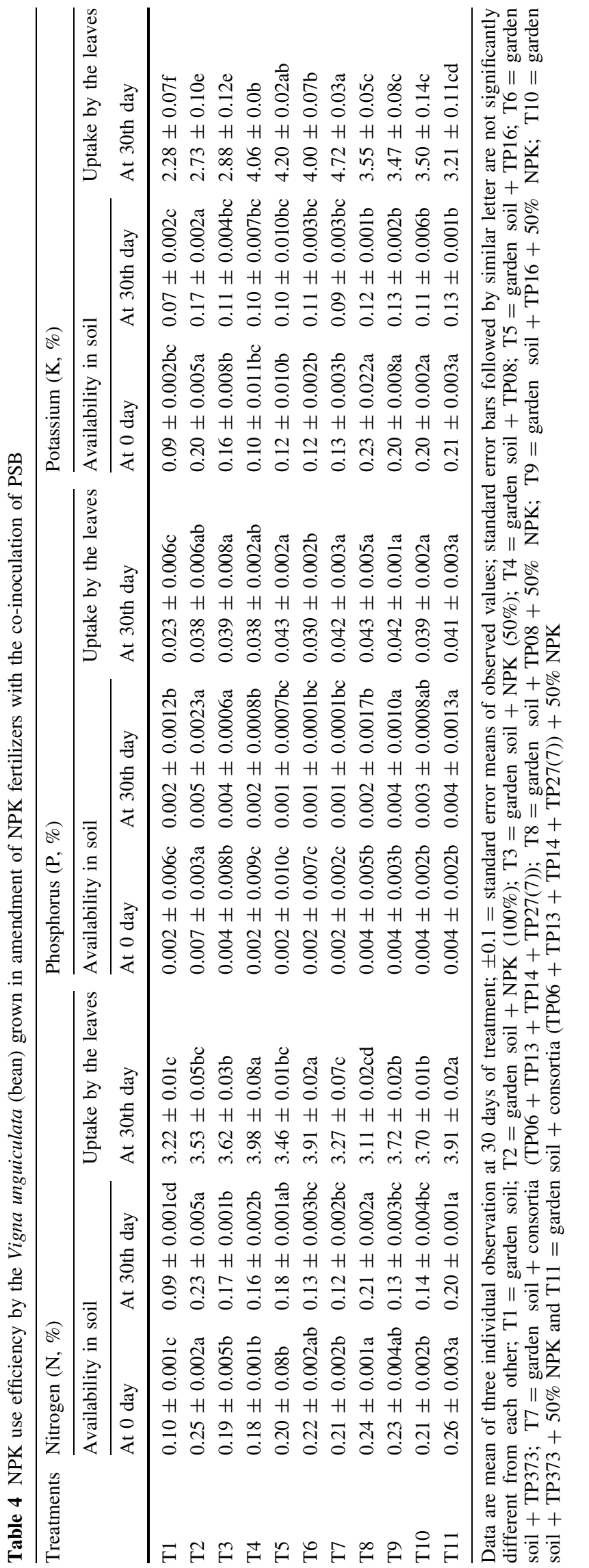

Table 5 Effect of inoculation of phosphorous solubilizing bacteria on germination index of Oryza sativa and Vigna unguiculata grown in different concentration of NPK fertilizer at 5th day

\begin{tabular}{lll}
\hline Treatments & \multicolumn{2}{l}{ Germination index (G. I.) } \\
\cline { 2 - 3 } & Oryza sativa & Vigna unguiculata \\
\hline $\mathrm{T} 1$ & $2.50 \pm 0.07 \mathrm{c}$ & $2.70 \pm 0.08 \mathrm{c}$ \\
$\mathrm{T} 2$ & $3.82 \pm 0.12 \mathrm{~b}$ & $3.40 \pm 0.11 \mathrm{~b}$ \\
$\mathrm{~T} 3$ & $3.87 \pm 0.09 \mathrm{~b}$ & $3.39 \pm 0.11 \mathrm{~b}$ \\
$\mathrm{~T} 4$ & $4.45 \pm 0.13 \mathrm{ab}$ & $3.50 \pm 0.22 \mathrm{~b}$ \\
$\mathrm{~T} 5$ & $4.90 \pm 0.08 \mathrm{a}$ & $3.10 \pm 0.10 \mathrm{~b}$ \\
$\mathrm{~T} 6$ & $4.37 \pm 0.10 \mathrm{ab}$ & $4.17 \pm 0.09 \mathrm{ab}$ \\
$\mathrm{T} 7$ & $4.98 \pm 0.07 \mathrm{a}$ & $4.70 \pm 0.12 \mathrm{a}$ \\
$\mathrm{T} 8$ & $4.45 \pm 0.09 \mathrm{~b}$ & $3.45 \pm 0.21 \mathrm{~b}$ \\
$\mathrm{~T} 9$ & $3.00 \pm 0.11 \mathrm{~b}$ & $3.90 \pm 0.06 \mathrm{ab}$ \\
$\mathrm{T} 10$ & $4.05 \pm 0.05 \mathrm{~b}$ & $4.03 \pm 0.11 \mathrm{ab}$ \\
$\mathrm{T} 11$ & $5.00 \pm 0.10 \mathrm{a}$ & $4.80 \pm 0.07 \mathrm{a}$ \\
\hline
\end{tabular}

Data are mean of three individual observation; $\pm 1.0=$ Standard error means of observed values; standard error followed by similar letter are not significantly different from each other; $\mathrm{T} 1=$ garden soil; $\mathrm{T} 2=$ garden soil $+\mathrm{NPK}(100 \%) ; \mathrm{T} 3=$ garden soil $+\mathrm{NPK}$ $(50 \%) ; \mathrm{T} 4=$ garden soil $+\mathrm{TP} 08 ; \mathrm{T} 5=$ garden soil $+\mathrm{TP} 16 ; \mathrm{T} 6=$ garden $\quad$ soil $+\mathrm{TP} 373 ; \quad \mathrm{T} 7=$ garden $\quad$ soil + consortia $\quad(\mathrm{TP} 06+$ $\mathrm{TP} 13+\mathrm{TP} 14+\mathrm{TP} 27(7)) ; \mathrm{T} 8=$ garden soil $+\mathrm{TP} 08+50 \% \mathrm{NPK} ;$ $\mathrm{T} 9=$ garden $\quad$ soil $+\mathrm{TP} 16+50 \% \quad \mathrm{NPK} ; \quad \mathrm{T} 10=$ garden $\quad$ soil + $\mathrm{TP} 373+50 \%$ NPK and T11 = garden soil + consortia $(\mathrm{TP} 06+$ TP13 + TP14 + TP 27(7)) + 50\% NPK

seed from $2.50 \pm 0.07$ to $5.00 \pm 0.10$; and in yardlong bean seed it is increased from $2.70 \pm 0.08$ to $4.80 \pm 0.07$ through the co-inoculation of PSB with or without the external application of recommended dose of NPK fertilizer. It is seen that the treatment where PSB and NPK were treated, had a higher G. I. than the control as well as in NPK treated soil without PSB. Several workers also reported about the improvement of germination of different plants while growing through inoculation of PGPR (Vessey 2003; Poonguzhali et al. 2006).

Induction of amylase activity

The effect of NPK amendment and the co-inoculation of PSB on induction of amylase activity in rice and bean plant is shown in Fig. 2a and b. It was seen that the amylase activity of the treatments containing the PSB (T4-T11) was found to be significantly higher $(p \leq 0.05)$ than that of the control and the NPK alone (T2 and T3). It was also observed that the amylase activity in the seeds $\left(58.4 \pm 2.2-94.4 \pm 3.0 \mu \mathrm{g} \mathrm{g}^{-1} \mathrm{~h}^{-1}\right)$ were much higher $(p \leq 0.01)$ than that in the leaves which was recorded from $2.20 \pm 1.1$ to $6.5 \pm 1.9 \mu \mathrm{g} \mathrm{g}^{-1} \mathrm{~h}^{-1}$. It is because of the more starch content in seed than the leaf which triggers the seed germination. During seed germination, amylase plays an important role in hydrolyzing the endosperm starch into 

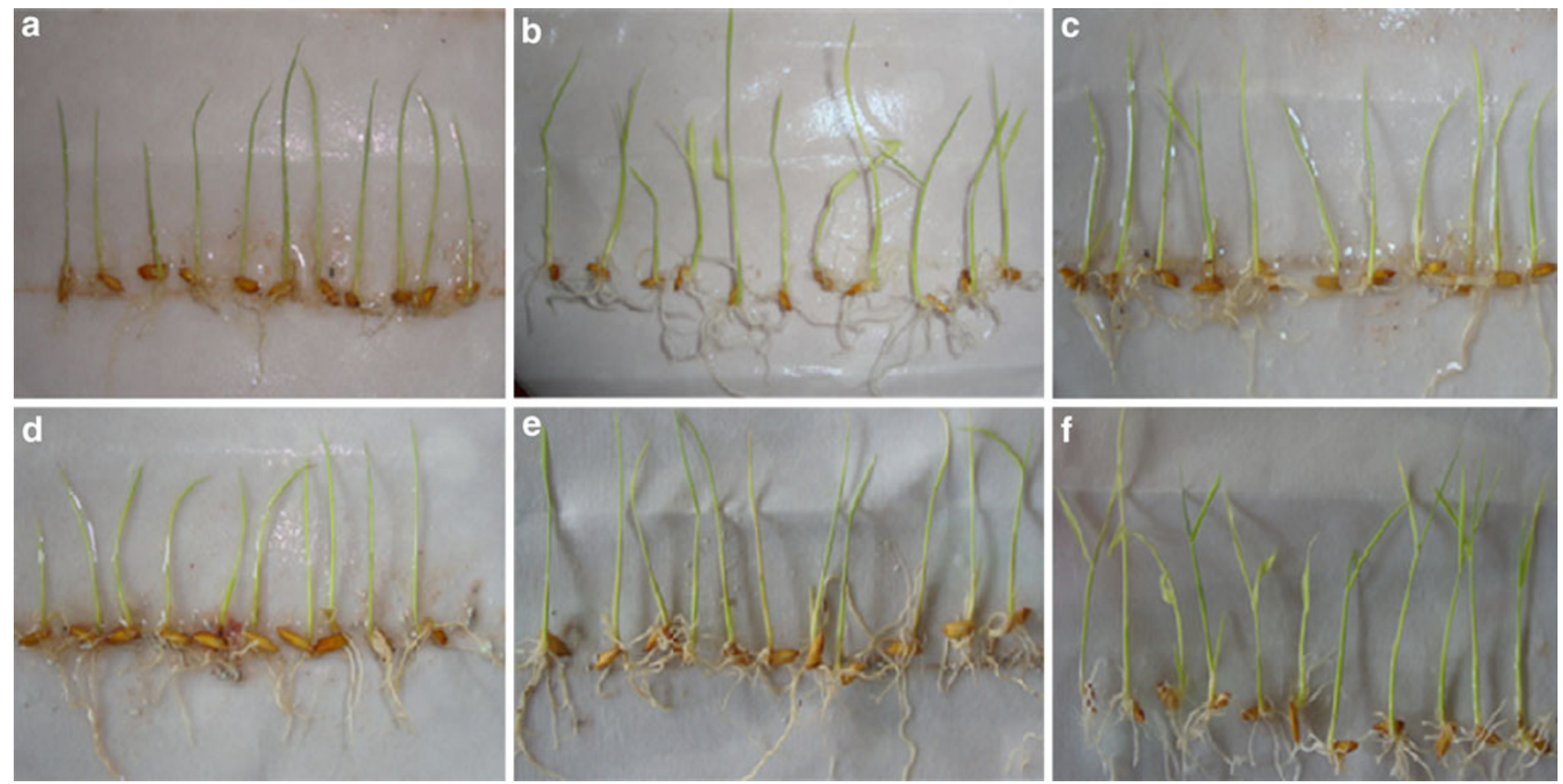

Fig. 1 Effect of inoculation of PSB on germination of Oryza sativa grown under amendment of NPK fertilizer. a T1 (Control), b T2 (100\% NPK), c T3 (50\% NPK), d T6 (TP373), e T7 (Consortia of PSB), f T11 (Consortia of PSB + NPK)

sugars which provide energy for the growth of roots and shoots (Beck and Ziegler 1989; Kaneko et al. 2002). Therefore, it can be said that the induction of amylase activity during germination can be increased through the co-inoculation of PSB with or without the externally applied NPK fertilizer, which helps in seed germination and thereby the better growth of the plant.

\section{Effect on growth}

It is also seen that the root length, shoot length and the total biomass of the plants of each treatment containing the PSB with or without NPK fertilizer after 15th day (at V3 stage) was recorded and found to be significantly higher $(p \leq 0.05)$ than that of the control and the NPK alone (T2 and T3) (Figs. 3, 4a, b). In case of the treatments containing only PSB, i.e., without the NPK amendment, the changes were more. Due to the solubilization of phosphorus by PSB there may be higher uptake of NPK, which results in a better growth of the plant. In all the PSB treated yardlong bean, an appreciably higher amount of fresh weight and dry weight was recorded. The total enhancement recorded (data not shown) in case of fresh weight when compared to the control are $\geq 17$ to $>237 \%$ in case of roots and 0.5 to $71 \%$ in case of shoots. For dry weight the enhancements are $\geq 2.0$ to $>227 \%$ in case of roots and $\geq 5$ to $157 \%$ in case of shoots. Highest root and shoot fresh weight was enhanced by the treatments TP373 and TP16; while in dry biomass for root and shoot was enhanced by the treatment through TP16 strain with 50\% NPK and $100 \%$ NPK amendment.

On the other hand, there was no enhancement of root fresh weight in rice for the treatments T6, T8 and T9 and also showed lower root fresh weight for the treatment T10 and T11 as compared to the control. But in longyard bean, a relatively higher fresh weight (both for shoot and root) was found for all the treatments than the control (data not shown). Similar result was seen in the case for root dry weight also. From this observation it could be conclude that in 50\% NPK, i. e., in reduced use of NPK and PSB treatment together achieved a higher growth than that of $100 \%$ NPK treatment alone. Thus, it can be predicted that the externally applied NPK fertilizer in excess amount or in recommended dose also is not may be beneficial for the crops. Similar use efficiency of NPK fertilizer by PSB and the utilization of PSB as biofertilizer in crop fields were earlier predicted by several workers (Rodriguez and Fraga 1999; Vessey 2003; Kennedy et al. 2004; Adesmoye and Kloepper 2009). Thus, use efficiency of NPK fertilizer can be improved through the application of PSB which helps in the growth of the plants through the uptake of NPK fertilizer.

\section{Conclusion}

Low microbial populations followed by low enzyme activities have been evident with the application of 

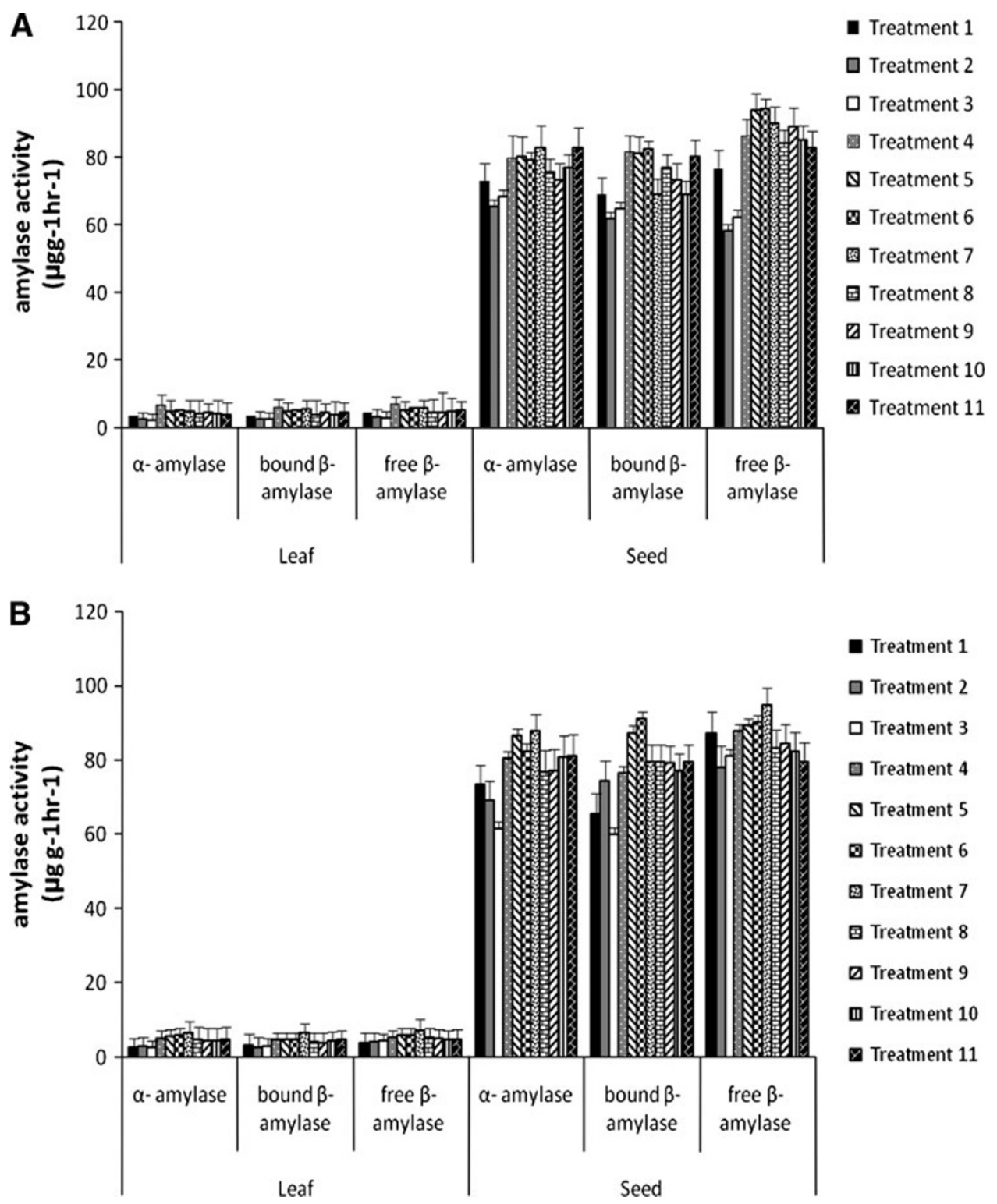

Fig. 2 a Effect of inoculation of phosphorous solubilizing bacteria on amylase activity on Oryza sativa grown in amendment of NPK fertilizers. Data are mean of three individual observation; error bars standard error means of observed values; $\mathrm{T} 1=$ garden soil; $\mathrm{T} 2=$ garden soil + NPK $(100 \%) ; \mathrm{T} 3=$ garden soil + NPK $(50 \%) ;$ $\mathrm{T} 4=$ garden soil $+\mathrm{TP} 08 ; \mathrm{T} 5=$ garden soil $+\mathrm{TP} 16 ; \mathrm{T} 6=$ garden soil + TP373; $\quad$ T7 $=$ garden $\quad$ soil + consortia $\quad($ TP06 + TP13 + $\mathrm{TP} 14+\mathrm{TP} \quad 27(7)) ; \quad \mathrm{T} 8=$ garden $\quad$ soil $+\mathrm{TP} 08+50 \% \quad \mathrm{NPK} ;$ $\mathrm{T} 9=$ garden soil $+\mathrm{TP} 16+50 \% \mathrm{NPK} ; \mathrm{T} 10=$ garden soil $+\mathrm{TP} 373+$ $50 \%$ NPK and $\mathrm{T} 11=$ garden soil + consortia $(\mathrm{TP} 06+\mathrm{TP} 13+$ TP14 + TP 27(7)) +50\% NPK. b Effect of inoculation of

excessive NPK fertilizers throughout this study. Our findings suggest that there is a strong relationship between fertilizer (NPK) and enzyme activity. Excessive use of NPK fertilizers leads to infertility of soil through a decreased level of microbial population with a subsequent decrease in dehydrogenase activity. Further, PSB phosphorous solubilizing bacteria on induction of amylase activity in Vigna unguiculata grown in amendment of NPK fertilizers. Data are mean of three individual observation; error bars standard error means of observed values; $\mathrm{T} 1=$ garden soil; $\mathrm{T} 2=$ garden soil + NPK $(100 \%) ;$ T3 = garden soil + NPK $(50 \%) ;$ T4 = garden soil + TP08; T5 = garden soil + TP16; T6 $=$ garden soil + TP373; $\mathrm{T} 7=$ garden soil + consortia $(\mathrm{TP} 06+\mathrm{TP} 13+\mathrm{TP} 14+\mathrm{TP} 27(7)) ;$ $\mathrm{T} 8=$ garden $\quad$ soil $+\mathrm{TP} 08+50 \% \quad \mathrm{NPK} ; \quad \mathrm{T} 9=$ garden $\quad$ soil + $\mathrm{TP} 16+50 \%$ NPK; T10 $=$ garden soil $+\mathrm{TP} 373+50 \% \mathrm{NPK}$ and $\mathrm{T} 11=$ garden $\quad$ soil + consortia $\quad(\mathrm{TP} 06+\mathrm{TP} 13+\mathrm{TP} 14+\mathrm{TP}$ $27(7))+50 \%$ NPK

applications increase the phosphatase and urease activities. Application of NPK fertilizers discourages this increment by reducing the population of PSB and nitrogen fixers. Moreover, the application of NPK in recommended dose or in its half dose gave the same results of soil enzyme activity, NPK uptake, germination and growth, with the 


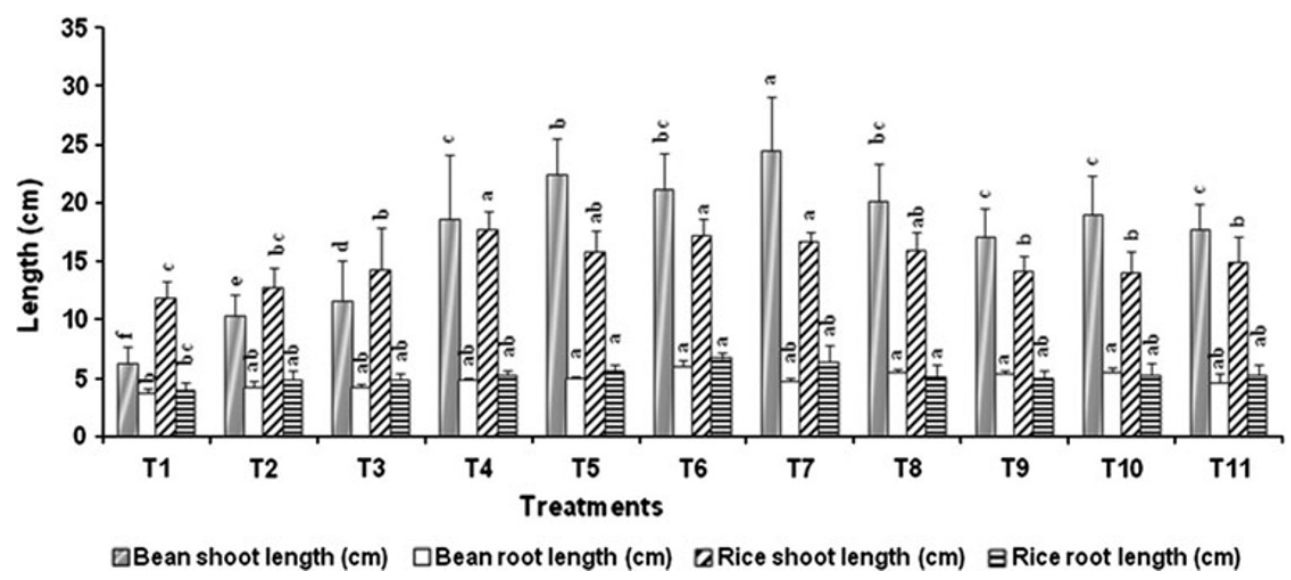

Fig. 3 Comparison of effect of inoculation of phosphate solubilizing bacteria on root length-shooot length of Oryza sativa (rice) and Vigna unguiculata (longyard bean) grown in amendment of fertilizer. Data are mean of three individual observation; error bars standard error means of observed values; standard error bars followed by similar letter are not significantly different from each other $\mathrm{T} 1=$ garden soil; $\mathrm{T} 2=$ garden soil + NPK $(100 \%) ; \mathrm{T} 3=$ garden soil + NPK $(50 \%) ;$
$\mathrm{T} 4=$ garden soil $+\mathrm{TP} 08 ; \mathrm{T} 5=$ garden soil $+\mathrm{TP} 16 ; \mathrm{T} 6=$ garden soil $+\mathrm{TP} 373 ; \quad \mathrm{T} 7=$ garden $\quad$ soil + consortia $(\mathrm{TP} 06+\mathrm{TP} 13+$ $\mathrm{TP} 14+\mathrm{TP} 27(7)) ; \mathrm{T} 8=$ garden soil $+\mathrm{TP} 08+50 \% \mathrm{NPK} ; \mathrm{T} 9=$ garden soil $+\mathrm{TP} 16+50 \%$ NPK; T10 $=$ garden soil $+\mathrm{TP} 373+$ $50 \%$ NPK and $\mathrm{T} 11=$ garden soil + consortia $(\mathrm{TP} 06+\mathrm{TP} 13+$ $\mathrm{TP} 14+\mathrm{TP} 27(7))+50 \% \mathrm{NPK}$
A
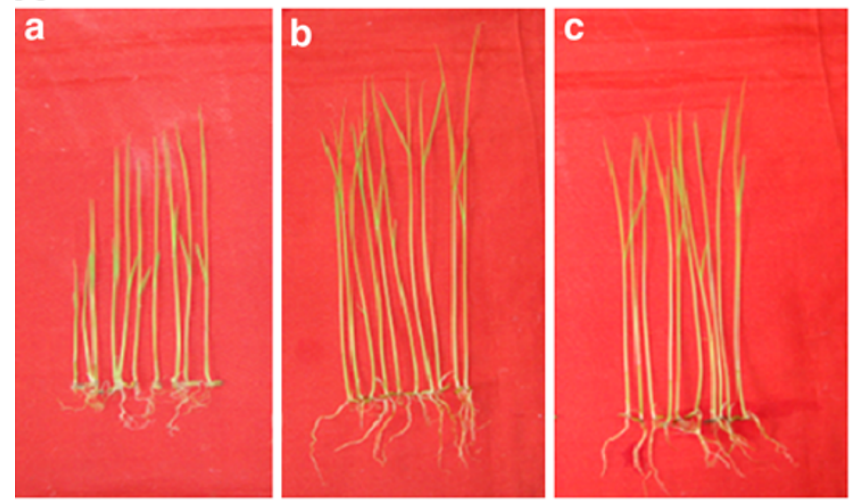

B
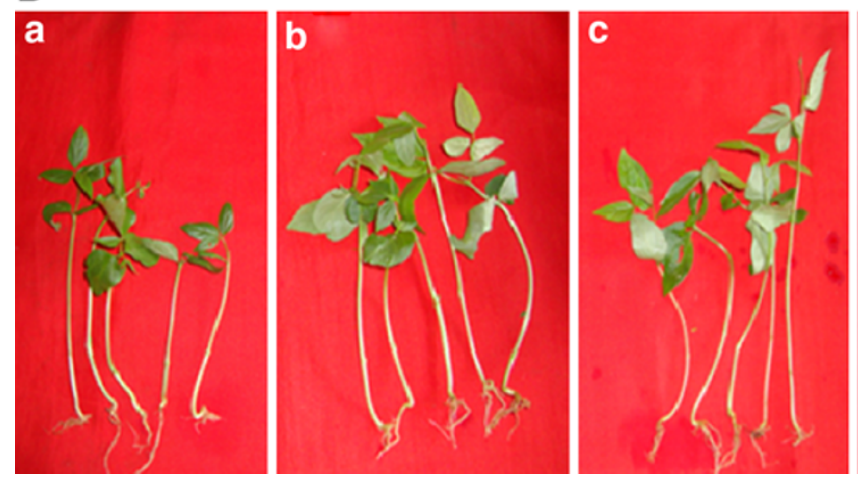

Fig. 4 Comparison of the effect of co-inoculation of PSB on growth of Oryza sativa and Vigna unguiculata grown in amendment of NPK fertilizers. A Effect on growth of Oryza sativa. B Effect on growth of

introduction of PSB which implies reduced application of agrochemicals. Thus, the application of PSB in crop fields may be much beneficial for the agriculturist.
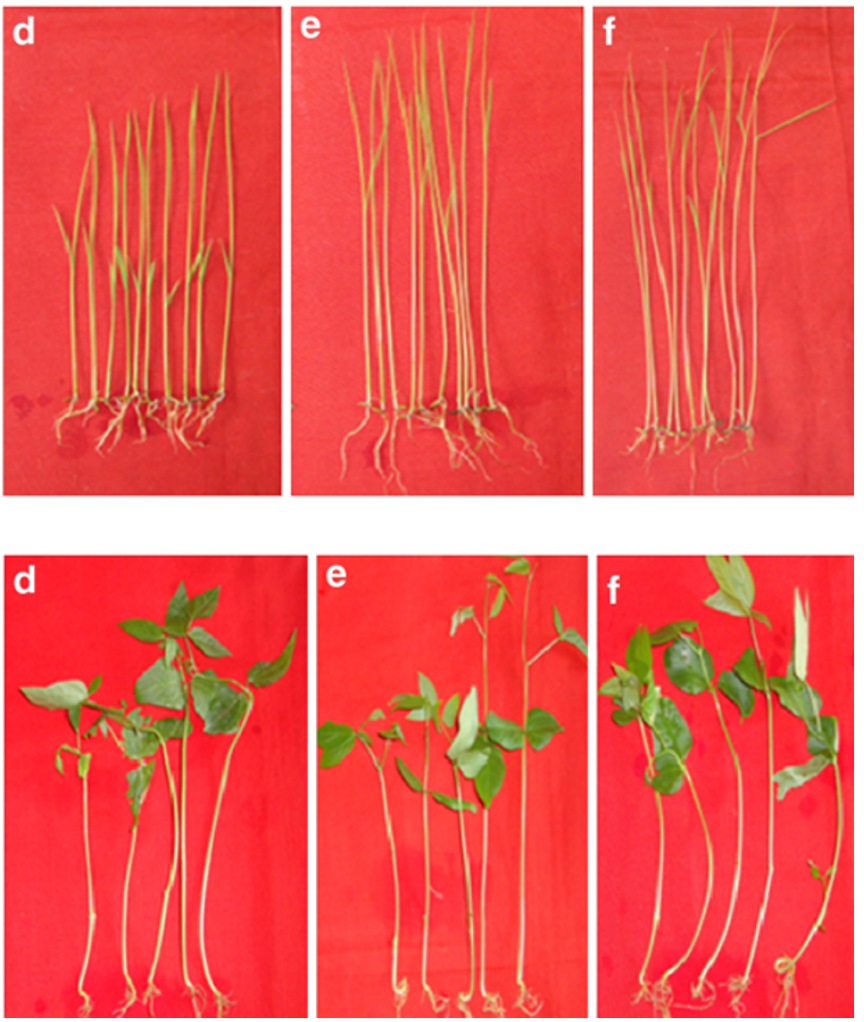

Vigna unguiculata. $a$ T1 (Control); $b$ T2 (100\% NPK); $c$ T3 (50\% NPK); $d$ T5 (PSB TP16); $e$ T7 (Consortia of PSB, viz., TP06, TP13, TP14, TP 27(7)); $f$ T11 (Consortia of PSB + NPK)

The uptake of NPK and plant growth promoting activity of PSB in both rice and yardlong bean can be explained by the occurrence of $\mathrm{P}$ solubilization as well as better 
scavenging of soluble $\mathrm{P}$ and other trace elements such as nitrogen, potassium, iron, zinc, etc. and also by production of plant growth promoting substances. Therefore, in support of the reduced application of NPK fertilizer and the high growth and yield of crops, the potential PSB strains can be employed as biofertilizing agents and to minimize the harmful effect of agrochemicals in the sustainable management of agriculture.

Acknowledgments We wish to express our sincere gratitude to the Director, NEIST, Jorhat, for his support to carrying out this investigation. We also gratefully acknowledge Department of Biotechnology, New Delhi, India for providing financial assistance.

Open Access This article is distributed under the terms of the Creative Commons Attribution License which permits any use, distribution and reproduction in any medium, provided the original author(s) and source are credited.

\section{References}

Adesmoye AO, Kloepper JW (2009) Plant-microbes interactions in enhanced fertilizer use efficiency. Appl Microbiol Biotechnol. doi10.1007/s00253-009-2196

Balamurugan A, Princy T, Pallavi RV, Nepolean Jayanthi PR, Premkumar R (2010) Isolation and characterization of phosphate solubilising bacteria in tea (Camellia sinensis). J Bio Sci Res 1(4):285-293

Baruah M, Mishra RR (1986) Effect of herbicides butachlor, 2,4-d and oxyfluorfen on enzyme activities and $\mathrm{CO}_{2}$ evolution in submerged paddy field soil. Plant Soil 96:287-291

Beck E, Ziegler P (1989) Biosynthesis and degradation of starch in higher plants. Annu Rev Plant Physiol Mol Biol 40:534-542

Casida DE (1964) Soil dehydrogenase activity. Soil Sci 98:371-376

Casida LE Jr (1977) Microbial metabolic activity in soil as measured by dehydrogenase determinations. Appl Environ Microbiol 34(6):630-636

Colmer TD (2003) Long distance transport of gases in plants: a perspective on internal aeration and radial oxygen loss from roots of rice (Oryza sativa L.) is reduced by growth of stagnant solution. J Exp Botany 49:1431-1436

Deka Boruah HP, Dileep Kumar BS (2002) Plant disease suppression and growth promotion by florescent Pseudomonas strain. Folia Microbiol 47(2):137-143

Elliott B (2001) Effect of seed quality on the performance of Argentine varieties in the 2001 regional test. Saskatoon Research Centre, Agriculture and Agri-Food Canada (Conducted at AAFC Saskatoon)

Fincher GB (1989) Molecular and cellular biology associated with endosperm mobilization in germinating cereal grains. Ann Rev Plant Physiol Plant Mol Biol 40:305-345

Glick BR (1995) The enhancement of plant growth by free-living bacteria. Can J Microbiol 41:109-117

Glick BR, Todorovic B, Czarny J, Cheng Z, Duan J, McConkey B (2007) Promotion of plant growth by bacterial ACC deaminase. Crit Rev Plant Sci 26:227-242

Gyaneshwar P, Kumar GN, Parekh LJ, Poole PS (2002) Role of soil microorganisms in improving $\mathrm{P}$ nutrition of plants. Plant Soil 245:83-93

Hariprasad P, Niranjana SR (2009) Isolation and characterization of phosphate solubilizing rhizobacteria to improve plant health of tomato. Plant Soil 316:13-24
Hong JP, Byan MY, An K, Yang SJ, An G, Woo Kim T (2010) OsKu70 is associated with developmental growth \& genomic stability of rice. Plant Physiol 152:374-384

Kaneko M, Itoh H, Miyako UT, Ashikari M, Matsuka M (2002) The $\alpha$-amylase induction in endosperm during rice seed germination is caused by gibberellin synthesized in epithelium. Plant Physiol 128:1264-1270

Kennedy IR, Choudhury ATMA, Kecskes ML (2004) Non-symbiotic bacteria diazotrophs in crop-farming systems: can their potential for plant growth promotion be better exploited? Soil Biol Biochem 36:1229-1244

Kim K, Yim WJ, Trivedi P, Madhaiyan M, Deka Boruah HP, Islam MR, Lee G, Sa TM (2009) Synergistic effects of inoculating arbuscular mycorrhizal fungi and Methylobacterium oryzae strains on growth and nutrient uptake of red pepper (Capsicum annum L). Plant Soil. doi10.1007/s11104-009-0072-4

Kloepper JW, Schroth MN (1978) Plant growth-promoting rhizobacteria on radishes, pp 879-882

Kucey RMN, Janzen HH, Leggett ME (1989) Microbially mediated increases in plant-available phosphorus. Ad Agron 42:199-228

Mc Garity JW, Myers MC (1967) A survey of urease activity in soils of Northern New South Wales. Plant Soil 27:217-238

Nahed G, Aziz AE (2007) Stimulatory effect of NPK fertilizer and Benzyladenine on growth and chemical constituents of Codiacum variegatum L plant. Am Euras J Agric Environ Sci 2(6):711-719

National Research Council (2006) Long bean: lost crops of Africa. Vegetables, vol II. National academic press, Washington

Paul AC, Terry CK, Mitchell AJ (2000) A uniform, objective and adaptive system for expressing rice development. Crop Sci 40(2):436-443. doi:10.2135/cropsci2000.402436x

Peix A, Rivas-Boyero AA, Mateos PF, Rodriguez-Barrueco C, Martinez-Molina E, Velazquez E (2001) Growth promotion of chickpea and barley by a phosphate solubilizing strain of Mesorhizobium mediterraneum under growth chamber conditions. Soil Biol Biochem 33:103-110

Pikovskaya RI (1948) Mobilization of phosphorus in soil in connection with vital activity of some microbial species. Microbiologiya $17: 362-370$

Poonguzhali S, Madhaiyan M, Sa TM (2006) Cultivation-dependent characterization of rhizobacterial communities from field grown Chinese cabbage Brassica campestris ssp. pekinensis and screening of traits for potential plant growth promotion. Plant soil 286:167-180

Poonguzhali S, Madhaiyan M, Sa TM (2007) Quorum-sensing signals produced by plant-growth promoting Burkholderia strains under in vitro and in-planta conditions. Res Microbiol 158:287-294

Richardson AE (2001) Prospects for using soil microorganism to improve the acquisition of phosphate by plant. Aust. J. Plant Physiol 28:897-906

Rodriguez H, Fraga R (1999) Phosphate solubilizing bacteria and their role in plant growth promotion. Biotchnol Adv 17:319-339

Suslow TV (1982) Role of root-colonizing bacteria in plant growth In: Mount MS, Lacy GH (eds), pp 187-223

Tabatabai MA, Bremner JM (1969) Use of $p$-nitrophenyl phosphate for assay of soil phosphatase activity. Soil Biol Biochem $1: 301-307$

Thiammaiah SR (2004) Standard methods of biochemical analysis. Kalyani publishers, Ludhiana, pp 186-187

Tilak KVBR, Ranganayaki N, Pal KK, De R, Saxena AK, Nautiyal CS, Mittal S, Tripathi AK, Johri BN (2005) Diversity of plant growth and soil health supporting bacteria. Curr Sci 89(1):136-150

Tilman D (1998) The greening of the green revolution. Nature 396:211-221 
Tilman D, Cassman KG, Matson PA, Naylor R, Polasky S (2002) Agricultural sustainability and intensive production practices. Nature 418:671-677

Trivedy RK, Goel PK, Trisal CL (1998) Practical methods in Ecology and Enviro media Series in methodology-2. Enviro media publication, Karad
Vessey JK (2003) Plant growth promoting rhizobacteria as biofertilizers. Plant Soil 255:571-586

Walkley A, Black A (1934) An examination of the Degtjareff method for determining soil organic matter and proposed modification of the chromic acid titration method. Soil Sci 37:29-37 